\title{
Human neural stem cell transplantation in spinal cord injury models: how far from clinical application?
}

Isaura Tavares ${ }^{1,2}$

See related research by van Gorp et al., http://stemcellres.com/content/4/3/57

\begin{abstract}
Injuries of the spinal cord trigger local healing but hardly restore normal function. Spinal cord injury (SCI) has been deeply studied to develop strategies for functional recovery. The study by van Gorp and colleagues uses a rat model of acute SCl to characterize the effects of intraspinal grafting of human fetal spinal cord-derived neural stem cells (HSSCs). Among the range of results obtained, several positive outcomes related to a GABA-mediated inhibition were achieved. Their interesting article is a clear step forward in elucidating the neurobiology of $\mathrm{SCl}$. Some issues to consider are related to the efficacy of the cell therapy in chronic spinal lesions and to pain responses, since the latter is a common complaint of people with SCl. Furthermore, the GABAmediated hypothesis of recovery of function upon HSSC transplant needs to be fully tested by interfering with GABA receptors and analyzing neurobiological mechanisms that may invert the inhibitory role of GABA. The future challenge for $\mathrm{SCl}$ work will be the translation of knowledge acquired in basic research into clinically applicable strategies. The study by van Gorp and colleagues is an important contribution to that future.
\end{abstract}

Correspondence: isatav@med.up.pt

'Department of Experimental Biology, Faculdade de Medicina do Porto, Alameda Hernani Monteiro, 4200-319, Porto, Portugal

${ }^{2}$ Instituto de Biologia Molecular e Celular (IBMC), Universidade do Porto, Rua do Campo Alegre 823, 4150-180, Porto, Portugal
Spinal cord injury (SCI) is a social and medical problem in modern societies. Research devoted to SCI has been very prolific: according to the Medline database, more than 6,310 articles were published in 2012 alone. Since the adult spinal cord has a limited regenerative capacity, neurobiological studies are crucial to an understanding of how neuronal spinal circuits can be reconstructed after an SCI to ensure function recovery and damage repair. The article by van Gorp and colleagues [1] is a detailed and eclectic study of several neurobiological issues in an acute experimental model of SCI induced by lumbar compression. The study uses human fetal spinal cord-derived neural stem cells (HSSCs) as a 'tool' to achieve function recovery and damage repair. The choice of HSSCs has a translational value since these cells have been used in clinical trials directed to disorders of the nervous system, like neurodegenerative diseases. The use of an acute model of SCI (rats that were injected with HSCCs only 3 days after lumbar lesion) is an interesting issue. After spinal cord lesion, a glial scar, which is considered the main chemical and physical barrier for axonal regeneration, arises [2]. An early delivery of HSSCs in the study by van Gorp and colleagues [1] is probably a crucial factor to prevent the formation of a large glial scar, which could account for the positive outcomes of cell therapy. It may be interesting to determine the deadline for HSSC transplantation in order to achieve a considerable function recovery after SCI as obtained by the authors [1].

In their study [1], transplantation of HSCCs ameliorated several parameters, such as spacity, sensory responses, and paw placement. However, other responses, such as the BBB score (Basso, Beattie, Bresnahan) locomotor score and ladder climbing, were not improved. This raises the question of the parameters which should be used in animal studies of SCI, taking into account the 
translational value of each parameter for SCI treatment [3]. One parameter which is especially challenging is the sensory threshold, namely that related to nociceptive (that is, potentially painful) responses. To evaluate pain responses, van Gorp and colleagues [1] determine the mechanical and thermal thresholds by using behavioral tests that involved brain modulation of the activity of spinal cord neurons. The authors do not detect SCIinduced hyperalgesia but rather hypoesthesia (that is, decreases in sensory responses), and this agrees with other studies [3]. Nor do the authors [1] discuss other studies that showed hyperalgesia (increased responses to painful stimuli) and allodynia (painful responses to normally innocuous stimuli) in models of SCI in areas outside the lesion site [4]. Rather than being contradictory, these differences in results reflect the challenge of studying evoked pain in animal models and reinforce the importance of developing methods to study spontaneous pain [5] given that chronic pain is a devastating condition that affects about $65 \%$ of patients with SCI [6]. In regard to the effects of SCI and cell therapy in the station relaying nociceptive information from the periphery to the brain (the spinal dorsal horn), the use of a standard marker of nociceptive activation of neurons located in that region would possibly have been effective. The induction of the c-fos proto-oncogene is considered a marker of nociceptive activation of spinal dorsal horn neurons, and the magnitude of its expression is directly correlated to behavioral responses to pain [7]. Studying the expression of the c-fos marker at several spinal cord levels could complement the study by van Gorp and colleagues [1] and determine gain or loss of neuronal function at the spinal dorsal horn after HSSC transplant.

The authors [1] analyze the mechanisms by which HSSCs improve function after SCI. A GABAmediated inhibition was proposed mainly on the basis of the inhibitory role of that neurotransmitter. However, GABA may be excitatory when the expression of the potassium chloride co-transporter (KCC2) is reduced, as demonstrated in models of inflammatory pain [8], traumatic neuropathic pain [9], and metabolic neuropathic pain [10]. By evaluating the expression of KCC2 expression in SCI, van Gorp and colleagues may be directed to search for nonGABAergic mechanisms that may explain the amelioration of function by HSSC transplant.

Their exciting article [1] has given the scientific community a lot to think about, and, best of all, a number of doable experiments may result from this study. Translational perspectives of the present findings can be considered only after thorough analysis of the efficacy and safety of the HSSCs in SCI models, preferably by using larger animals. The answers to the questions raised by this article are of the highest import for the advancement of the field of regenerative medicine and the treatment of injuries of the spinal cord.

Note: This article is part of a thematic series on Clinical applications of stem cells edited by Mahendra Rao. Other articles in the series can be found online at http://stemcellres.com/ series/clinical.

\section{Abbreviations}

HSSC: human fetal spinal cord-derived neural stem cell; SCl: spinal cord injury.

\section{Competing interests}

The author declares that she has no competing interests.

Published: 13 June 2013

\section{References}

1. van Gorp S, Leerink M, Kakinnohana O, Platoshyn O, Santucci C, Joosten E, Hruska-Plochani M, Goldbergi D, Marsala S, Johe K, Marsala M: Amelioration of motor/sensory dysfunction and spasticity in a rat model of acute lumbar spinal cord injury by human neural stem cell transplantation. Stem Cell Res Ther. in press.

2. Bradbury EJ, Moon LD, Popat RJ, King VR, Bennett GS, Patel PN, Fawcett JW, McMahon SB: Chondroitinase $A B C$ promotes functional recovery after spinal cord injury. Nature 2002, 416:636-640.

3. Baastrup C, Maersk-Moller CC, Nyengaard JR, Jensen TS, Finnerup NB: Spinal-, brainstem- and cerebrally mediated responses at- and belowlevel of a spinal cord contusion in rats: evaluation of pain-like behavior. Pain 2010, 151:670-679.

4. Whitt JL, Masri R, Pulimood NS, Keller A: Pathological activity in mediodorsal thalamus of rats with spinal cord injury pain. $J$ Neurosci 2013, 33:3915-3926.

5. Mogil JS, Davis KD, Derbyshire SW: The necessity of animal models in pain research. Pain 2010, 151:12-17.

6. Hulsebosch CE, Hains BC, Crown ED, Carlton SM: Mechanisms of chronic central neuropathic pain after spinal cord injury. Brain Res Rev 2009, 60:202-213.

7. Coggeshall RE: Fos, nociception and the dorsal horn. Prog Neurobiol 2005, 77:299-352.

8. Anseloni VC, Gold MS: Inflammation-induced shift in the valence of spinal GABA-A receptor-mediated modulation of nociception in the adult rat. $J$ Pain 2008, 9:732-738.

9. Coull J, Boudreau D, Bachand K, Prescott S, Nault F, Sik A, De Koninck P, De Koninck Y: Trans-synaptic shift in anion gradient in spinal lamina I neurons as a mechanism of neuropathic pain. Nature 2003, 424:923-942.

10. Morgado C, Pinto-Ribeiro F, Tavares I: Diabetes affects the expression of GABA and potassium chloride co-transporter in the spinal cord: a study in streptozotocin diabetic rats. Neurosci Lett 2008, 438:102-106.

doi: $10.1186 /$ scrt210

Cite this article as: Tavares: Human neural stem cell transplantation in spinal cord injury models: how far from clinical application?. Stem Cell Research \& Therapy 2013 4:61. 